\title{
Evaluasi Penggunaan Material Bekisting Kayu Pada Proyek Pembangunan Gedung FKIP Universitas Jambi
}

\author{
Mohamad Andy Zakaria, Fakhrul Rozi Yamali*, Annisaa Dwiretnani \\ Fakultas Teknik Sipil Universitas Batanghari Jambi \\ *Correspondence email: fakhrul_65@yahoo.co.id
}

\begin{abstract}
Abstrak. Bangunan gedung memiliki berbagai unsur seperti tanah dasar, pondasi, sloof, balok, kolom, dinding, lantai, dan atap. Dalam proses pekerjaan unsur - unsur bangunan gedung dibutuhkan, Rencana Anggaran Biaya (RAB), Material, draft gambar, dan Sumber Daya Manusia (SDM). Material, merupakan salah satu komponen penting dalam proyek kontruksi. Berhasil atau tidaknya suatu proyek konstruksi bangunan gedung, salah satunya ditentukan oleh kualitas pengelolaan material dalam menunjang keberhasilan suatu proyek. Lokasi penelitian berada pada Pembangunan Gedung FKIP Universitas Jambidi Jl. Lintas jambimuaro burlian Km. 15, Mendalo Darat, Jambi Luar Kota, Kota Jambi, Provinsi Jambi. Penelitian dilakukan dengan cara menganalisa RAB, Analisa Harga Satuan Pekerjaan, Laporan Pembelian Material. Berdasarkan penelitian, material bekisting kayu kelas III yang dibeli oleh pihak kontraktor sebanyak 46,71 $\mathrm{m}^{3}$ dan yang digunakan sebanyak 18,18 $\mathrm{m}^{3}$. Kayu kelas II yang dibeli oleh pihak kontraktor sebanyak 15, $23 \mathrm{~m}^{3}$ dan yang digunakan sebanyak 7,32 $\mathrm{m}^{3}$. Untuk Plywood pihak kontraktor membeli sebanyak 830 lbr dan yang digunakan sebanyak 160 lbr. Sedangkan untuk kayu galam pihak kontraktor membeli sebanyak 608 btg dan digunakan seluruhnya. Semua material yang digunakan untuk pekerjaan plat lantai dan b. k lantai 3.
\end{abstract}

Kata kunci: Bekisting Kayu, Rancangan Anggaran Biaya (RAB), Bangunan Gedung

\section{PENDAHULUAN}

Proyek Pembangunan Gedung FKIP Universitas Jambi ini terdiri dari 3 lantai. Dengan perencanaan Lantai 1 seluas $1512 \mathrm{~m}^{2}$, lantai 2 seluas $1464 \mathrm{~m}^{2}$, lantai 3 seluas $1464 \mathrm{~m}^{2}$. Proyek ini dibangun pada lahan Luas areal lahan $4587,2 \mathrm{~m}^{2}$. Pada pelaksanaan proyek konstruksi bangunan gedung komponen yang sangat penting adalah pekerjaan struktur. Berdasarkan permasalahan tersebut penulis akan melakukan penelitian tentang penggunaan bekisting kayu pada proyek pembangunan Gedung Fakultas Keguruan dan Ilmu Pengetahuan (FKIP) Universitas Jambi.

\section{Pengertian Bekisting}

Menurut Stephens (1985), formwork atau bekisting adalah cetakan sementara yang digunakan untuk menahan beton selama beton dituang dan dibentuk sesuai dengan bentuk yang diinginkan. Dikarenakan berfungsi sebagai cetakan sementara, bekisting akan dilepas atau dibongkar apabila beton yang dituang telah mencapai kekuatan yang cukup.

\section{Jenis-Jenis Bekisting \\ Bekisting Konvensional}

Bekisting Konvesional adalah jenis bekisting yang pertama kali dikenal. Bekisting konvensional atau bekisting tradisional hanya mengandalkan triplek dan kayu atau papan. Jenis papan yang dipakai biasanya adalah papan yang tahan kelembaban. Papan bekisting dari kayu yang umum digunakan memiliki ketebalan $2 \mathrm{~cm}$ saMpai $3 \mathrm{~cm}$ dengan lebar $15 \mathrm{~cm}$ saMpai $20 \mathrm{~cm}$. Sementara itu untuk ketebalan triplek bekisting sekitar $3 \mathrm{~mm}$ saMpai $9 \mathrm{~mm}$.

\section{Bekisting Knock Down}

Seiring perkembangan teknologi khususnya di bidang rancang bangun, berbagai inovasi dilakukan termasuk yang berkaitan dengan pekerjaan bekisting. Salah satu inovasi penting di dunia rancang bangun adalah munculnya sistem bekisting knock down. Sistem bekisting knock down ini menggunakan bahan besi hollow dan plat baja. Tentunya penggunaan material tersebut akan menghasilkan bentuk yang lebih presisi jika dibandingkan dengan penggunaan triplek dan papan pada sistem bekisting konvensional.

\section{Bekisting Fiberglass}

Pilihan jenis bekisting moderen lainnya adalah bekisting fiberglass. Bekisting yang terbuat dari bahan fiberglass ini tahan terhadap air sehingga sangat cocok dipakai pada konstruksi di bawah tanah. Selain itu, bahan fiberglass tidak mudah berkarat, ramah lingkungan, ringan, mudah dibersihkan, mudah dipasang dan juga mudah dilepas. 
Mohamad Andy Zakaria, Fakhrul Rozi Yamali dan Annisaa Dwiretnani, Evaluasi Penggunaan Material Bekisting Kayu Pada Proyek Pembangunan Gedung FKIP Universitas Jambi

\section{Material Bekisting}

Adapun material bekisting yang sering digunakan dalam proyek konstruksi bangunan gedung :

\section{Multipleks (Plywood)}

Secara umum terdapat 3 jenis multipleks (Plywood) yang sering digunakan sebagai material bekisting beton yaitu multipleks biasa, multipleks Poly Resin (Poly Film), dan multipleks Film Face (Phenolic Film).

a. Multipleks Biasa

b. Multipleks Poly Resin

c. Multipleks Film Face ( Phenolic Film )

\section{Kayu}

Dalam dunia konstruksi, kayu merupakan bahan bekisting yang banyak digunakan, khususnya pada bekisting konvensional dimana keseluruhan bahan bekisting dibuat dari kayu. Begitu juga dengan bekisting semi konvensional, dimana material kayu masih banyak digunakan meski penggunaan kayu papan telah digantikan oleh Plywood. Untuk menghasilkan hasil beton yang sesuai dengan yang direncanakan, maka diperlukan acuan mengenai jenis kuat $\mathrm{kayu}_{2}$ sehingga syarat kekuatan dan kekakuan kayu masih dalam batas-batas yang diijinkan.

\section{Biaya Material Bekisting}

Biaya material adalah salah satu komponen biaya yang terbesar dalam suatu proyek konstruksi dimana porsinya dapat mencapai $50-60 \%$ dari total nilai proyek. Pembiayaan pada bekisting berkisar antara 35\% hingga $60 \%$ dari seluruh biaya struktur beton. Pengaruh biaya pekerjaan bekisting terhadap biaya pekerjaan struktur beton, merupakan hal yang harus di rencanakan agar pekerjaan bekisting lebih ekonomis (Nawy, 1997).

\section{Persyaratan Bekisting}

Perancangan bekisting perlu memperhatikan syarat-syarat tertentu yang mendukung kualitasnya. Di bawah ini sejumlah persyaratan yang harus dipenuhi oleh bekisting yang baik :

1. Konstruksinya Kuat

2. Ketetapan Bentuk

3. Tidak Bocor

4. Bersifat Kedap Air

5. GaMpang Dibongkar

\section{Rancangan Anggaran Biaya}

$\mathrm{RAB}$ adalah perhitungan rincian biaya yang diperlukan untuk setiap pekerjaan dalam proyek konstruksi, sehingga diperoleh estimasi biaya total yang diperlukan untuk menyelesaikan proyek tersebut.

a. Fungsi dan Pentingnya Rencana Anggaran Biaya (RAB)

Membuat RAB sebelum mengerjakan proyek merupakan hal yang penting RAB berfungsi sebagai acuan dasar pelaksanaan proyek, mulai dari pemilihan kontraktor yang sesuai, pembelian bahan bangunan, saMpai pengawasan proyek agar berjalan sesuai dengan rancangan dan kesepakatan awal Anda dengan kontraktor.

b. Rincian yang Harus Ada di Dalam RAB

Idealnya dalam pembuatan RAB, ada beberapa rincian yang dimasukkan ke dalam tabel. Namun rincian ini pun tak harus Anda masukkan semuanya ke dalam RAB, tergantung dari jenis perhitungan yang sesuai dengan proyek Anda.

\section{Rumus Perhitungan}

a. Jumlah Kebutuhan Bekisting Balok = Koef. Analisa Bahan X Koef. Begisting X Vol. Pekerjaan

b. Jumlah Kebutuhan Bekisting Plat Lantai = Koef. Analisa Bahan X Koef. Begisting X Vol. Pekerjaan

c. Rekapitulasi Perbandingan RAB dan Laporan Pembelian Material $=$ Kebutuhan Material berdasarkan RAB - Laporan Pembelian Material

\section{METODE}

Tahapan penelitian merupakan urutan langkah/tata cara yang dilaksanakan secara sistematis dan logis sesuai dasar teori permasalahan sehingga didapat analisis yang akurat untuk mencapai tujuan penelitian.

Tahapan-tahapan penelitian yang dilakukan adalah sebagai berikut: 
1. Tahap Persiapan

Langkah yang dilakukan adalah merumuskan masalah penelitian, menentukan tujuan penelitian dan melakukan studi pustaka yaitu dengan membaca materi kuliah, buku-buku referensi, buku-buku skripsi, dan jurnal yang berhubungan dengan pembuatan laporan penelitian.

2. Tahap Pengumpulan Data

Langkah yang dilakukan adalah mengumpulkan data sekunder yang dijadikan obyek penelitian dari kontraktor pelaksana. Data penelitian yang diperlukan adalah Gambar Rencana, RAB, Analisa Harga Satuan dan Laporan Pembelian Material. Untuk mendukung penelitian dilakukan wawancara langsung dengan kontraktor di lapangan.

3. Tahap Analisis Data Langkah yang dilakukan adalah:

a. Menghitung Volume kebutuhan material bekisting berdasarkan RAB

b. Menghitung Volume pembelian material Bekisting berdasarkan laporan Pembelian material Bekisting.

c. Menghitung Perbandingan Biaya Material berdasarkan RAB dan Laporan Pembelian Material.

d. Menghitung Persentase Material yang dapat digunakan Kembali

e. Menghitung persentase Keuntungan Kontraktor.

4. Tahap Pembahasan

Langkah yang dilakukan adalah membahas hasil penelitian mengenai evaluasi Penggunaan material Bekisting

Kayu Proyek Gedung Fakultas Keguruan Dan Ilmu Pendidikan Universitas Jambi.

\section{Lokasi Penelitian}

Lokasi penelitian adalah berada pada Pembangunan Gedung FKIP Universitas Jambidi Jl. Lintas jambi- muaro burlian Km. 15, Mendalo Darat, Jambi Luar Kota, Kota Jambi, Provinsi Jambi.

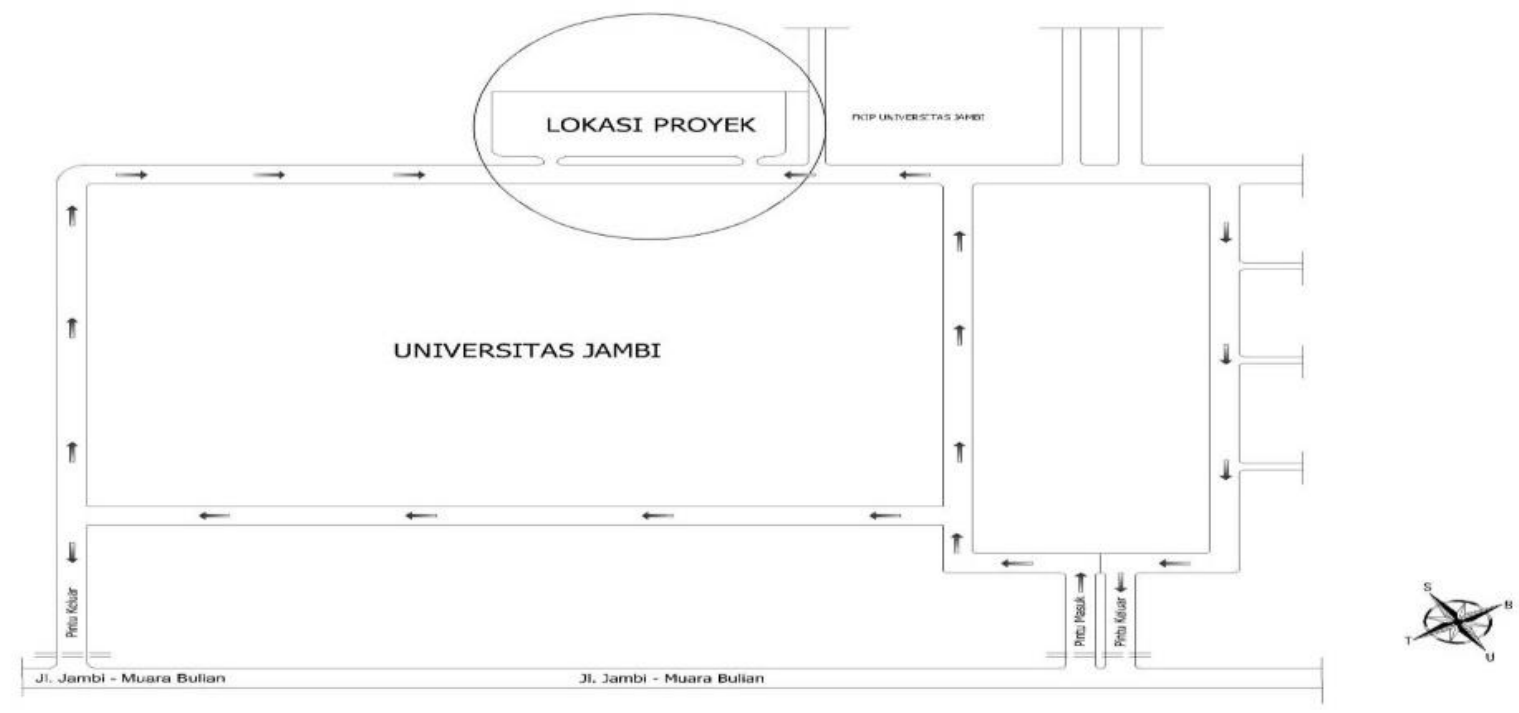

Sumber : Data Olahan (2019)

Gambar 1. Denah Lokasi Penelitian

\section{HASIL DAN PEMBAHASAN}

Perhitungan Vol. Material Kayu dan Plywood Plat Lantai T.12 cm Beton Bertulang Fc = 31,2 Mpa besi 207 $\mathrm{Kg} / \mathrm{m}^{3}$ $\mathrm{m}^{3}$

Perhitungan Pekerjaan Plat Lantai T.12 cm Beton Bertulang Fc = 31,2 Mpa besi $207 \mathrm{Kg} / \mathrm{m}^{3}$ dengan vol. 69,11

1. Menghitung vol. kayu kelas III plat lantai $T .12 \mathrm{~cm}$

Koefisien Bahan untuk Plat lantai $=0,0400 \mathrm{~m}^{3}$

Koefisien Bekisting untuk Plat Lantai $=4,1700 \mathrm{~m}^{2}$

Vol. kayu kelas III seluruh plat lantai $=0,0400 \mathrm{~m}^{3}$ x 4,1700 $\mathrm{m}^{2} \times 69,11 \mathrm{~m}^{3}$

$=11,53 \mathrm{~m}^{3}$

2. Menghitung vol. kayu kelas II plat lantai T.12 cm

Koefisien untuk Plat lantai $=0,0150 \mathrm{~m}^{3}$

Koefisien Bekisting untuk Plat Lantai $=4,1700 \mathrm{~m}^{2}$ 
Vol. kayu kelas II seluruh plat lantai $=0,0150 \mathrm{~m}^{3}$ x 4,1700 $\mathrm{m}^{2}$ x $69,11 \mathrm{~m}^{3}$ $=4,32 \mathrm{~m}^{3}$

3. Menghitung vol. Plywood plat lantai T.12 cm

Koefisien untuk Plat lantai $=0,3500 \mathrm{lbr}$

Koefisien Bekisting untuk Plat Lantai $=4,1700 \mathrm{~m}^{2}$

Vol. kayu kelas III seluruh plat lantai $=0,3500 \mathrm{lbr} x 4,1700 \mathrm{~m}^{2} 69,11 \mathrm{~m}^{3}$

$=100,87 \mathrm{lbr}$

4. Menghitung vol. Dolken Kayu Galam plat lantai T.12 cm

Koefisien untuk Plat lantai $=2,000$ btg

Koefisien Bekisting untuk Plat Lantai $=4,1700 \mathrm{~m}^{2}$

Vol . kayu kelas III seluruh plat lantai $=2,000 \mathrm{btg} \times 4,1700 \mathrm{~m}^{2} \times 69,11 \mathrm{~m}^{3}$

$=1729,13 \mathrm{btg}$

\section{Perhitungan Vol. Material Kayu dan Plywood Balok B1 25/40 Beton Bertulang fc = 31,2 Mpa Besi $147 \mathrm{Kg} / \mathrm{m}^{3}$}

Perhitungan Pekerjaan Balok B1 25/40 Beton Bertulang $\mathrm{Fc}=31,2 \mathrm{Mpa}$ besi $147 \mathrm{Kg} / \mathrm{m}^{3}$ dengan vol. $24,20 \mathrm{~m}^{3}$

1. Menghitung vol. kayu kelas III Balok B1 25/40

Koefisien Bahan untuk Balok B1 25/40 =0,0400 $\mathrm{m}^{3}$

Koefisien Bekisting untuk Balok B1 25/40 =4,0500 $\mathrm{m}^{2}$

Vol. kayu kelas III seluruh Balok B1 25/40 $=0,04 \mathrm{~m}^{3}$ x 4,0500 $\mathrm{m}^{2}$ x 24,20 $\mathrm{m}^{3}$

$=3,92 \mathrm{~m}^{3}$

2. Menghitung vol. kayu kelas II Balok B1 25/40

Koefisien untuk Balok B1 25/40 =0,0180 $\mathrm{m}^{3}$

Koefisien Bekisting untuk Balok B1 25/40 $=4,0500 \mathrm{~m}^{2}$

Vol kayu kelas II seluruh Balok B1 25/40 =0,0180 $\mathrm{m}^{3}$ x 4,05 $\mathrm{m}^{2} \times 24,20 \mathrm{~m}^{3}$

$=1,76 \mathrm{~m}^{3}$

3. Menghitung vol. Plywood Balok B1 25/40

Koefisien untuk Balok B1 25/40 = 0,3500 lbr

Koefisien Bekisting untuk Balok B1 25/40 $=4,0500 \mathrm{~m}^{2}$

Vol. kayu kelas III seluruh Balok B1 25/40 = 0,35 lbr x 4,05 $\mathrm{m}^{2}$ x 24,20 $\mathrm{m}^{3}$

$=34,31 \mathrm{lbr}$

4. Menghitung vol. Dolken Kayu Galam Balok B1 25/40

Koefisien untuk Balok B1 25/40 = 2,000 btg

Koefisien Bekisting untuk Balok B1 25/40 $=4,0500 \mathrm{~m}^{2}$

Vol. dolken kayu galam Balok B1 25/40 =2,00 btg x 4,05 $\mathrm{m}^{2}$ x 24,20 $\mathrm{m}^{3}$

$=196,04 \mathrm{btg}$

Perhitungan Vol. Material Kayu dan Plywood Balok B2 25/50 Beton Bertulang fc = 31,2 Mpa Besi 139 Kg/m3 Perhitungan Pekerjaan Balok B2 25/50 Beton Bertulang fc $=31,2 \mathrm{Mpa}$ Besi $139 \mathrm{Kg} / \mathrm{m}^{3}$ dengan vol. 6,20 m

1. Menghitung vol. kayu kelas III Balok B2 25/50

Koefisien untuk Balok B2 25/50 =0,0400 $\mathrm{m}^{3}$

Koefisien Bekisting untuk Balok B2 25/50 $=4,0500 \mathrm{~m}^{2}$

Vol. kayu kelas III seluruh Balok B2 25/50 =0,04 m3 x 4,05 m2 x 6,20 m

$=1,00 \mathrm{~m}^{3}$

2. Menghitung vol. kayu kelas II Balok B2 25/50

Koefisien untuk Balok B2 25/50 =0,0180 $\mathrm{m}^{3}$

Koefisien Bekisting untuk Balok B2 25/50 = 4,0500 $\mathrm{m}^{2}$

Vol. kayu kelas II seluruh Balok B2 25/50=0,018 $\mathrm{m}^{3}$ x 4,05 $\mathrm{m} 2$ × 6,20 $\mathrm{m}^{3}$

$=0,45 \mathrm{~m}^{3}$

3. Menghitung vol. Plywood Balok B2 25/50

Koefisien untuk Balok B2 25/50 =0,3500 lbr

Koefisien Bekisting untuk Balok B2 25/50 $=4,0500 \mathrm{~m}^{2}$

Vol. Plywood seluruh Balok B2 25/50 =0,3500 lbr x 4,05 $\mathrm{m}^{2}$ x 6,20 $\mathrm{m}^{3}$ $=8,79 \mathrm{lbr}$

4. Menghitung vol. Dolken Kayu Galam Balok B2 25/50

Koefisien untuk Balok B2 25/50 = 2,000 btg

Koefisien Bekisting untuk Balok B2 25/50 $=4,0500 \mathrm{~m}^{2}$

Vol. Kayu galam seluruh Balok B2 25/50 =2,000 btg x 4,05 $\mathrm{m}^{2}$ x 6,20 $\mathrm{m}^{3}$ 
Mohamad Andy Zakaria, Fakhrul Rozi Yamali dan Annisaa Dwiretnani, Evaluasi Penggunaan Material Bekisting Kayu

$=50,22 \mathrm{btg}$

Perhitungan Vol. Material Kayu dan Plywood Balok B3 30/60 Beton Bertulang fc = 31,2 Mpa Besi $109 \mathrm{Kg} / \mathrm{m}^{3}$ Perhitungan Pekerjaan Balok B3 30/60 Beton Bertulang fc $=31,2 \mathrm{Mpa}$ Besi $109 \mathrm{Kg} / \mathrm{m}^{3}$ dengan vol. 1,98 $\mathrm{m}^{3}$

1. Menghitung vol. kayu kelas III Balok B3 30/60

Koefisien untuk Balok B3 30/60 =0,0400 $\mathrm{m}^{3}$

Koefisien Bekisting untuk Balok B3 30/60 =4,0500 $\mathrm{m}^{2}$

Vol. kayu kelas III seluruh Balok B3 30/60 =0,0400 $\mathrm{m}^{3}$ x 4,05 $\mathrm{m} 2 \times 1,98 \mathrm{~m}^{3}$

$=0,32 \mathrm{~m}^{3}$

2. Menghitung vol. kayu kelas II Balok B3 30/60

Koefisien untuk Balok B3 30/60 = 0,0180 $\mathrm{m}^{3}$

Koefisien Bekisting untuk Balok B3 30/60 $=4,0500 \mathrm{~m}^{2}$

Vol. kayu kelas II seluruh Balok B3 30/60 =0,0180 $\mathrm{m}^{3}$ x 4,05 $\mathrm{m}^{2}$ x 1,98 $\mathrm{m}^{3}$

$=0,14 \mathrm{~m}^{3}$

3. Menghitung vol. Plywood Balok B3 30/60

Koefisien untuk Balok B3 30/60 = 0,3500 lbr

Koefisien Bekisting untuk Balok B3 30/60 =4,0500 m²

Vol. kayu kelas III seluruh Balok B3 30/60 =0,3500 lbr x 4,05 $\mathrm{m}^{2}$ x 1,98 $\mathrm{m}^{3}$

$=2,81 \mathrm{lbr}$

4. Menghitung vol. Dolken Kayu Galam Balok B3 30/60

Koefisien untuk Balok B3 30/60 $=2,000$ btg

Koefisien Bekisting untuk Balok B3 30/60 $=4,0500 \mathrm{~m}^{2}$

Vol. kayu kelas III seluruh Balok B3 30/60 $=2,000$ btg x 4,05 $\mathrm{m}^{2}$ x 1,98 $\mathrm{m}^{3}$

$=16,04 \mathrm{btg}$

Perhitungan Vol. Material Kayu dan Plywood Balok B5 40/60 Beton Bertulang fc = 31,2 Mpa Besi $82 \mathrm{Kg} / \mathrm{m}^{3}$ Perhitungan Pekerjaan Balok B5 40/60 Beton Bertulang fc $=31,2 \mathrm{Mpa}$ Besi $82 \mathrm{Kg} / \mathrm{m}^{3}$ dengan vol. 11,21 $\mathrm{m}^{3}$

1. Menghitung vol. kayu kelas III Balok B5 40/60

Koefisien untuk Balok B5 40/60 =0,0400 $\mathrm{m}^{3}$

Koefisien Bekisting untuk Balok B5 40/60 $=2,8300 \mathrm{~m}^{2}$

Vol. kayu kelas III seluruh Balok B5 40/60 =0,04 m3 x 2,83 $\mathrm{m}^{2} \times 11,21 \mathrm{~m}^{3}$

$=1,27 \mathrm{~m}^{3}$

2. Menghitung vol. kayu kelas II Balok B5 40/60

Koefisien untuk Balok B5 40/60 =0,0180 $\mathrm{m}^{3}$

Koefisien Bekisting untuk Balok B5 40/60 =2,8300 $\mathrm{m}^{2}$

Vol. kayu kelas II seluruh Balok B5 40/60 =0,0180 $\mathrm{m}^{3}$ x 2,83 $\mathrm{m}^{2}$ x 11,21 $\mathrm{m}^{3}$

$=0,57 \mathrm{~m}^{3}$

3. Menghitung vol. Plywood Balok B5 40/60

Koefisien untuk Balok B5 40/60 = 0,3500 lbr

Koefisien Bekisting untuk Balok B5 40/60 =2,8300 $\mathrm{m}^{2}$

Vol. Plywood seluruh Balok B5 40/60 =0,3500 lbr x 2,83 $\mathrm{m}^{2}$ x 11,21 $\mathrm{m}^{3}$

$=11,10 \mathrm{lbr}$

4. Menghitung vol. Dolken Kayu Galam Balok B5 40/60

Koefisien untuk Balok B5 40/60 = 2,000 btg

Koefisien Bekisting untuk Balok B5 40/60 =2,8300 $\mathrm{m}^{2}$

Vol. kayu galam seluruh Balok B5 40/60 = 2 btg x 2,83 $\mathrm{m}^{2} \times 11,21 \mathrm{~m}^{3}$

$=63,44 \mathrm{btg}$

Perhitungan Vol. Material Kayu dan Plywood Balok BA 20/35 Beton Bertulang fc $=31,2 \mathrm{Mpa}$ Besi $176 \mathrm{Kg} / \mathrm{m}^{3}$ Perhitungan Pekerjaan Balok BA 20/35 Beton Bertulang fc $=31,2 \mathrm{Mpa}$ Besi $176 \mathrm{Kg} / \mathrm{m}^{3}$ dengan vol. 0,83 $\mathrm{m}^{3}$

1. Menghitung vol. kayu kelas III Balok BA 20/35

Koefisien untuk Balok BA 20/35 =0,0400 $\mathrm{m}^{3}$

Koefisien Bekisting untuk Balok BA 20/35 $=4,0500 \mathrm{~m}^{2}$

Vol. kayu kelas III seluruh Balok BA 20/35 =0,0400 $\mathrm{m}^{3}$ x $0,04 \mathrm{~m}^{2}$ x 0,83 $\mathrm{m}^{3}$

$=0,13 \mathrm{~m}^{3}$

2. Menghitung vol. kayu kelas II Balok BA 20/35

Koefisien untuk Balok BA 20/35 $=0,0180 \mathrm{~m}^{3}$ 
Mohamad Andy Zakaria, Fakhrul Rozi Yamali dan Annisaa Dwiretnani, Evaluasi Penggunaan Material Bekisting Kayu Pada Proyek Pembangunan Gedung FKIP Universitas Jambi

Koefisien Bekisting untuk Balok BA 20/35 $=4,0500 \mathrm{~m}^{2}$

Vol. kayu kelas II seluruh Balok BA 20/35 =0,0180 $\mathrm{m}^{3} \times 0,04 \mathrm{~m}^{2} \times 0,83 \mathrm{~m}^{3}$

$=0,06 \mathrm{~m}^{3}$

3. Menghitung vol. Plywood Balok BA 20/35

Koefisien untuk Balok BA 20/35 =0,3500 lbr

Koefisien Bekisting untuk Balok BA 20/35 $=4,0500 \mathrm{~m}^{2}$

Vol. kayu kelas III seluruh Balok BA 20/35 =0,3500 lbr x 4,05 $\mathrm{m}^{2}$ x 0,83 $\mathrm{m}^{3}$

$=1,18 \mathrm{lbr}$

4. Menghitung vol. Dolken Kayu Galam Balok BA 20/35

Koefisien untuk Balok BA 20/35 $=2,000$ btg

Koefisien Bekisting untuk Balok BA 20/35 $=4,0500 \mathrm{~m}^{2}$

Vol. kayu kelas III seluruh Balok BA 20/35 =2,000 btg x 4,05 $\mathrm{m}^{2}$ x 11,21 $\mathrm{m}^{3}$

$=6,75 \mathrm{btg}$

\section{Berdasarkan Laporan Pembelian}

Perhitungan dengan metode ini menggunakan Laporan pembelian yang direkap perbulan, lalu didapat total jumlah vol. masing-masing material.

Sumber : Data Olahan (2019)

Tabel 1. Rekap Laporan Pembelian Kebutuhan Bekisting Plywood

\begin{tabular}{ccc}
\hline No & Ukuran Plywood & Jumlah (Lbr) \\
\hline 1 & Triplex $5 \mathrm{~m} / \mathrm{m} \mathrm{85}$ & 20 \\
2 & Triplex $8 \mathrm{~m} / \mathrm{m} 100$ & 100 \\
3 & Triplex $5 \mathrm{~m} / \mathrm{m} 85$ & 30 \\
4 & Triplek $8 \mathrm{~mm}$ & 250 \\
5 & Triplek $8 \mathrm{~mm}$ & 200 \\
6 & Triplek $8 \mathrm{~mm}$ & 130 \\
7 & Triplek $8 \mathrm{~mm}$ & 100 \\
\hline & Total & $\mathbf{8 3 0}$ \\
\hline
\end{tabular}

\section{Perbandingan Hasil Kedua Metode Perhitungan}

Pada sub-bab ini membandingkan hasil dari metode perhitungan RAB Pembangunan Gedung FKIP Universitas Jambi dengan Laporan pembelian dari kontraktor.

Tabel 2. Perbandingan Material Bekisting Kayu Dan Plywood Antara RAB Dan Laporan Pembelian

\begin{tabular}{crrrrrc}
\hline No. & Material & Satuan & RAB & Laporan Pembelian & selisih & Harga (Rp) \\
\hline $\mathbf{1}$ & Kayu Kelas III & $\mathrm{m}^{3}$ & $\mathbf{1 8 , 1 8}$ & $\mathbf{4 6 , 7 1}$ & $\mathbf{2 8 , 5 3}$ & $\mathbf{5 7 . 0 6 0 . 0 0 0}$ \\
$\mathbf{2}$ & Kayu Kelas II & $\mathrm{m}^{3}$ & $\mathbf{7 , 3 2}$ & $\mathbf{1 5 , 2 3}$ & $\mathbf{7 , 9 1}$ & $\mathbf{3 1 . 6 4 0 . 0 0 0}$ \\
$\mathbf{3}$ & Plywood & $\mathrm{Lbr}$ & $\mathbf{1 6 0}$ & $\mathbf{8 3 0}$ & $\mathbf{6 7 0}$ & $\mathbf{8 3 . 7 5 0 . 0 0 0}$ \\
$\mathbf{4}$ & Kayu Dolken & $\mathrm{Btg}$ & $\mathbf{2 0 6 2}$ & $\mathbf{6 0 8}$ & $\mathbf{1 , 4 5 4}$ & $\mathbf{7 . 6 3 3 . 5 0 0}$ \\
\hline
\end{tabular}

Sumber : Data Olahan (2019)

\section{SIMPULAN}

Berdasarkan penelitian, material bekisting kayu kelas III yang dibeli oleh pihak kontraktor sebanyak $46,71 \mathrm{~m}^{3}$ dan yang digunakan sebanyak $18,18 \mathrm{~m}^{3}$. Kayu kelas II yang dibeli oleh pihak kontraktor sebanyak $15,23 \mathrm{~m}^{3}$ dan yang digunakan sebanyak $7,32 \mathrm{~m}^{3}$. Untuk Plywood pihak kontraktor membeli sebanyak $830 \mathrm{lbr}$ dan yang digunakan sebanyak 160 lbr. Sedangkan untuk kayu galam pihak kontraktor membeli sebanyak 608 btg dan digunakan seluruhnya. Semua material yang digunakan untuk pekerjaan plat lantai dan balok lantai 3.

\section{DAFTAR PUSTAKA}

Ananda Rahman Arief P, 2018. Analisis Perbandingan Efisiensi Penggunaan Metode Bekisting Konvensional Dengan Metode Bekisting Semi-Sistem Perkuatan Besi Hollow Pada Proyek Hotel Ibis Surabaya. Tugas Akhir. Universitas Muhammadiyah Malang. Malang.

Anindya, Ajeng Ayu. 2016. Analisis Perbandingan Biaya Dan Waktu Penggunaan Bekisting Plywood Berlapis Polyfilm Dan Bekisting Pvc Pada Proyek Bangunan Gedung. Tugas Akhir. Universitas Atma Jaya. Yogyakarta. Dipohusodo, I, 1996, Struktur Beton Berlulang, Berdasarlcan SK SNI T15- 1991-03 Deparlemen Pekefjaan Umum RI. Penerbit Gramedia Pustaka Utama, Jakarta.

Hanna Awad S, 1999. Concrete Formwork System, Marcel Dekker. University of Wisconsin, New York. 
Mohamad Andy Zakaria, Fakhrul Rozi Yamali dan Annisaa Dwiretnani, Evaluasi Penggunaan Material Bekisting Kayu Pada Proyek Pembangunan Gedung FKIP Universitas Jambi

Nawy, E.G. 1997. Concrete Construction Engineering. CRC Press. New York.

Nugroho, Agung Wahyu. 2014. Analisa Produktivitas Pekerjaan Pelat Lantai M-Panel, Beton Bertulang, Dan Sni Pekerjaan Pelat Beton Bertulang. Universitas Brawijaya:Malang.

Nugroho, Sony Prakoso . 2018. Analisis Perbandingan Biaya Bekisting Antara Bekisting Multiplek Dan Bekisting Tegofilm Untuk Kolom Gedung Bertingkat. Tugas Akhir. Univeritas Islam Indonesia:Yogyakarta.

Pratama, Hario Surya. 2017. Analisa Perbandingan Penggunaan Bekisting Konvensional, Semi Sistem, Dan Sistem (Peri) Pada Kolom Gedung Bertingkat. Jurnal Karya Teknik Sipil. Universitas Diponegoro.

Peraturan Konstruksi Kayu Indonesia N5-PKKI1961. 1961. Departemen Pekerjaan Umum.

Suhendra. 2010. Analisa Satuan Bahan Pekerjaan Bekisting Beton Bertulang: Studi Kasus Pada Pekerjaan Bangunan Gedung. Jurnal Ilmiah Universitas Batanghari Jambi Vol.10 No.3 Tahun 2010 Universitas Batanghari:Jambi.

Stephens, 1985. Pengertian Bekisting, http:/e-journal.uajy.ac.id. Diakses tanggal 22 Agustus 2019.

Sutaryo dan KUsdjono, 1984. Kamus Istilah Teknik Sipil. Departemen Pendidikan dan Kebudayaan Direktorat Jendral Pendidikan Dasar dan Menengah, Jakarta.

Wiguna, I Made Pandu Weda. 2018. Analisis Penghematan Biaya Penggunaan Bekisting Pelat Lantai Konvensional Model Panel Pada Bangunan Tipikal (Studi Kasus Pada Proyek Amartha Residence). Jurnal Spektran Vol. 6, No. 1, Januari 2018. Universitas Udayana.

Wigbout, F. Ing. 1997. Bekisting (Kotak Cetak). Jakarta : Penerbit Erlangga. 